\title{
Processing and Characterization of GaSb/High-k Dielectric Interfaces
}

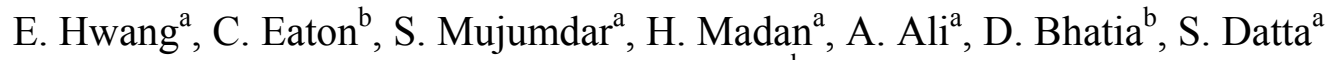 \\ and J. Ruzyllo, \\ ${ }^{a}$ Department of Electrical Engineering, Pennsylvania State University, University Park, \\ Pennsylvania 16802, USA \\ ${ }^{\mathrm{b}}$ Department of Materials Science and Engineering, Pennsylvania State University, \\ University Park, Pennsylvania 16802, USA
}

The GaSb surface was exposed to various HCl-based chemical treatments in order to prepare it for high-k dielectric integration. The chemical and structural analysis was performed by X-ray photoelectron spectroscopy (XPS) and atomic force microscopy (AFM). The chemical analysis indicates the $\mathrm{HCl}$ effectively removes native oxide from GaSb surface and leaves it slightly antimony rich. The structural study reveals that the surface roughness increases upon the reexposure to air after the HCl-based surface treatment. Additional information was obtained from photo-conductance decay (PCD) measurements as well as $\mathrm{C}-\mathrm{V}$ measurements of metal- $\mathrm{Al}_{2} \mathrm{O}_{3}-\mathrm{GaSb}$ capacitors.

\section{Introduction}

Recently, antimonide-based compound semiconductors are being pursued for their potential usefulness in next generations' low-power logic applications (1,2,3). Among them, n-type InAsy $\mathrm{Sb}_{1-y}$ quantum-well field effect transistors (QWFETs) in conjunction with p-type $\operatorname{In}_{\mathrm{x}} \mathrm{Ga}_{1-\mathrm{x}} \mathrm{Sb}$ QWFETs are of interest for low-power complementary logic applications $(4,5)$. A thin layer of $\mathrm{GaSb}$ is formed on top of $\mathrm{Al}_{0.8} \mathrm{In}_{0.2} \mathrm{Sb}$ barrier layer to avoid Al interaction with the dielectric and the associated surface oxidation. In such a configuration, $\mathrm{GaSb}$ is a material surface properties of which are of critical importance in the process of high-k dielectric integration.

The GaSb surface is chemically very reactive and as such forms a few nanometerthick films of Ga-oxide and Sb-oxide. Upon exposure to air GaSb surface will form a native oxide consisting of $\mathrm{Ga}_{2} \mathrm{O}_{3}$ and $\mathrm{Sb}_{2} \mathrm{O}_{3}$ according to the reaction $(6,7)$

$$
2 \mathrm{GaSb}+3 \mathrm{O}_{2} \rightarrow \mathrm{Ga}_{2} \mathrm{O}_{3}+\mathrm{Sb}_{2} \mathrm{O}_{3}
$$

Subsequently, $\mathrm{Sb}_{2} \mathrm{O}_{3}$ reacts with $\mathrm{GaSb}$ forming additional $\mathrm{Ga}_{2} \mathrm{O}_{3}$ and elemental $\mathrm{Sb}$ which are the only stable phases that can exist in thermodynamic equilibrium.

$$
2 \mathrm{GaSb}+\mathrm{Sb}_{2} \mathrm{O}_{3} \rightarrow \mathrm{Ga}_{2} \mathrm{O}_{3}+\mathrm{Sb}
$$

This reaction occurs even at room temperature and the resultant elemental $\mathrm{Sb}$ can form a thin metallic layer, thus increasing the surface leakage (7). This property of GaSb 
significantly hampers the integration of GaSb with high-k gate dielectrics and causes high interface trap density.

It is known that the HCl-based surface treatment effectively removes both Ga-oxide and $\mathrm{Sb}$-oxide from $\mathrm{GaSb}$ surface (8). However, the impact of the direct $\mathrm{HCl}$ exposure needs to be further explored to evaluate its effect of surface morphology as well as properties of high-k dielectric-GaSb interface. The goal of this study is to investigate the effectiveness of the HCl-based surface treatment in the preparation of oxide-free, flat $\mathrm{GaSb}$ surfaces adequate for thin high-k dielectric atomic layer deposition (ALD).

\section{Experimental}

In this experiment, Te-doped, (100)-oriented, 2-inch GaSb substrates were used. In the preliminary examination of the effect of HCl-based surface cleaning, two different preALD surface treatments were investigated: Process 1 in which GaSb wafers were only degreased in acetone and isopropanol for $5 \mathrm{~min}$, and Process 2 in which wafers were degreased and then etched in $\mathrm{HCl}(1): \mathrm{H}_{2} \mathrm{O}(2)$ solution for $10 \mathrm{~min}$ then rinsed in isopropanol alcohol. After the surface cleaning, samples were blown with nitrogen and subjected to XPS (X-Ray Photoelectron Spectroscopy) and AFM (Atomic Force Microscopy) analysis. The XPS analysis was carried out using Kratos Axis Ultra XPS with a monochromatic $\mathrm{Al} \mathrm{K \alpha}$ X-ray source. The binding energy (BE) was calculated using

$$
\mathrm{BE}=h v-\mathrm{KE}-\varphi
$$

where $h v$ is the excitation energy, $\mathrm{KE}$ is the measured kinetic energy of the ejected electrons and $\varphi$ is the work function of the spectrometer.

Next in this experiment the GaSb MOS capacitors with $\mathrm{Al}_{2} \mathrm{O}_{3}$ as a dielectric were fabricated for electrical characterization of $\mathrm{Al}_{2} \mathrm{O}_{3}-\mathrm{GaSb}$ interfaces. The $\mathrm{GaSb}$ substrates were loaded into $\mathrm{ALD}$ chamber where $5 \mathrm{~nm}$ thick $\mathrm{Al}_{2} \mathrm{O}_{3}$ was deposited at $300^{\circ} \mathrm{C}$ by cyclic pulses of trimethylaluminum (TMA) and $\mathrm{H}_{2} \mathrm{O}$ (TMA first process). The process of MOS capacitors fabrication was completed by e-beam evaporation of $\mathrm{Pt} / \mathrm{Au}$ gate contacts and $\mathrm{Pd} / \mathrm{Au}$ back contacts. Forming gas anneal (FGA) was carried out under forming gas $\left(96 \% \mathrm{~N}_{2}+4 \% \mathrm{H}_{2}\right)$ at $350^{\circ} \mathrm{C}$ for 30 minutes. Additional electrical characterization was carried out on $\mathrm{Al}_{2} \mathrm{O}_{3}-\mathrm{GaSb}$ samples using photo-conductance decay (PCD) method described in details in Ref. (9).

\section{Results and Discussion}

Figure 1 shows the XPS results in the Ga $2 \mathrm{p}_{3 / 2}$ and $\mathrm{Sb} 3 \mathrm{~d}_{3 / 2}$ regions after two different cleaning procedures employed in this study. Samples in Process 1 show the presence of both Ga-oxide and Sb-oxide (Fig. 1a). Oxide coverage is greatly reduced in the case of Process 2 (Fig. 1b) indicating effective oxide removal by $\mathrm{HCl}(1): \mathrm{H}_{2} \mathrm{O}(2)$ solution. However, the resulting surface is slightly antimony rich. Hence, a potential concern is the increase of the peak representing elemental $\mathrm{Sb}$ (Fig.1b) resulting from the reaction of Sb- 
oxide in contact with $\mathrm{GaSb}$ wafer as elemental $\mathrm{Sb}$ can form a thin metallic layer which will create a surface leakage path (7).

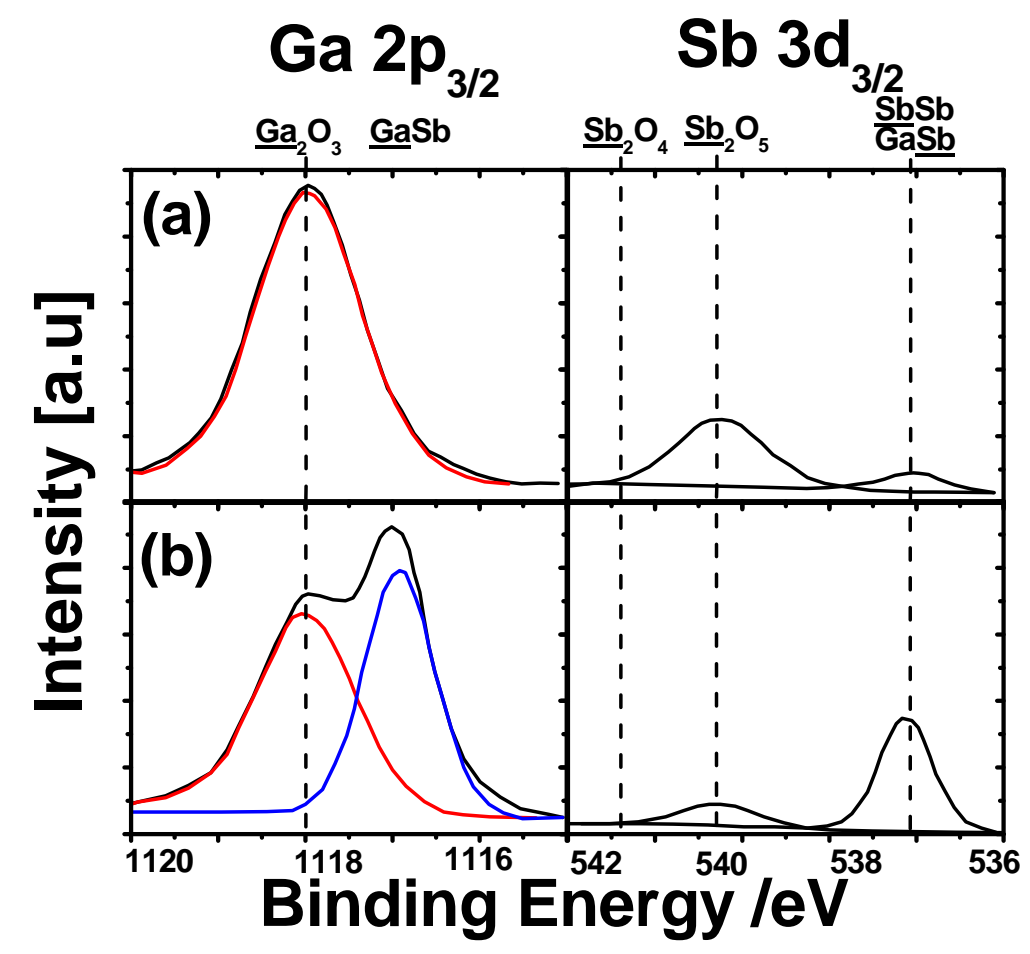

Figure 1. XPS spectra of $\mathrm{Ga} 2 \mathrm{p}_{3 / 2}$ and $\mathrm{Sb} 3 \mathrm{~d}_{3 / 2}$ before and after the HCl-based surface treatments. (a) GaSb sample after being degreased (Process 1) and (b) being dipped in $\mathrm{HCl}$ for 10 minutes and rinsed by isopropanol alcohol (Process 2).

The surface roughness of samples from two different surface treatments was measured by AFM. The scan area is $1 \times 1 \mu \mathrm{m}^{2}$. The results for as-received GaSb sample after being degreased (Process 1), yielded root-mean-square (rms) surface roughness of $\sim 0.75 \mathrm{~nm}$. The surface roughness increased to $\sim 3.8 \mathrm{~nm}$ after samples being dipped in $\mathrm{HCl}$ for 10 minutes. Based on the AFM measurements performed in this study it is suggested that the reexposure of the $\mathrm{HCl}$-treated $\mathrm{GaSb}$ surface to air causes the irregular growth of oxide islands, thereby, increasing the surface roughness. The possible roughening of the $\mathrm{GaSb}$ surface is a critical factor in the preparation of the flat GaSb surface for successful integration with high-k dielectric.

Figure 2 shows the capacitance voltage $(\mathrm{C}-\mathrm{V})$ characteristics for $\mathrm{GaSb}$ MOS capacitors representing two processes investigated. Figure 2 a shows the $\mathrm{C}-\mathrm{V}$ curves for Process 1 which indicate that the Fermi level is strongly pinned and very fast interface traps alter the response of the MOS capacitor. Figure $2 b$ shows the C-V curves for Process 2 where improved Fermi level modulation is observed. However, it still exhibits the high density of interface trap in both the accumulation and inversion mode. To suppress the effect of interface trap, the sample from Process 2 was subsequently annealed in forming gas $\left(4 / 96 \%: \mathrm{H}_{2} / \mathrm{N}_{2}\right)$ at $350^{\circ} \mathrm{C}$ for 30 minutes and the resulting $\mathrm{C}-\mathrm{V}$ characteristics are shown in Fig. 2c. After FGA, the interface trap density in the negative bias regime appears to be reduced. On the other hand, however, the maximum capacitance was decreases as well suggesting the increase of the thickness of the interfacial oxide. 


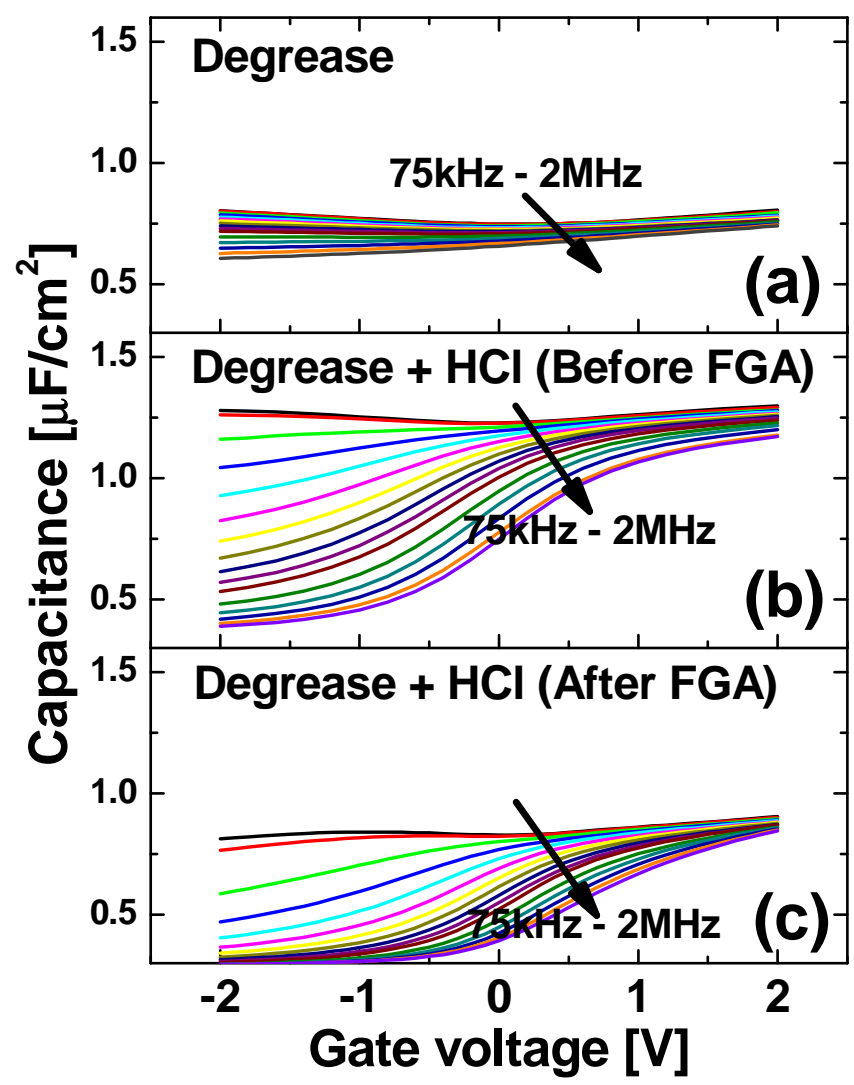

Figure 2. C-V characteristics as a function of frequency of n-type GaSb MOS capacitors (a) after the degrease step (Process 1), (b) after HCl-based surface treatment (Process 2) and (c) after $\mathrm{HCl}$-based surface treatment (Process 2) and forming gas anneal at $350^{\circ} \mathrm{C}$ for 30 minutes.

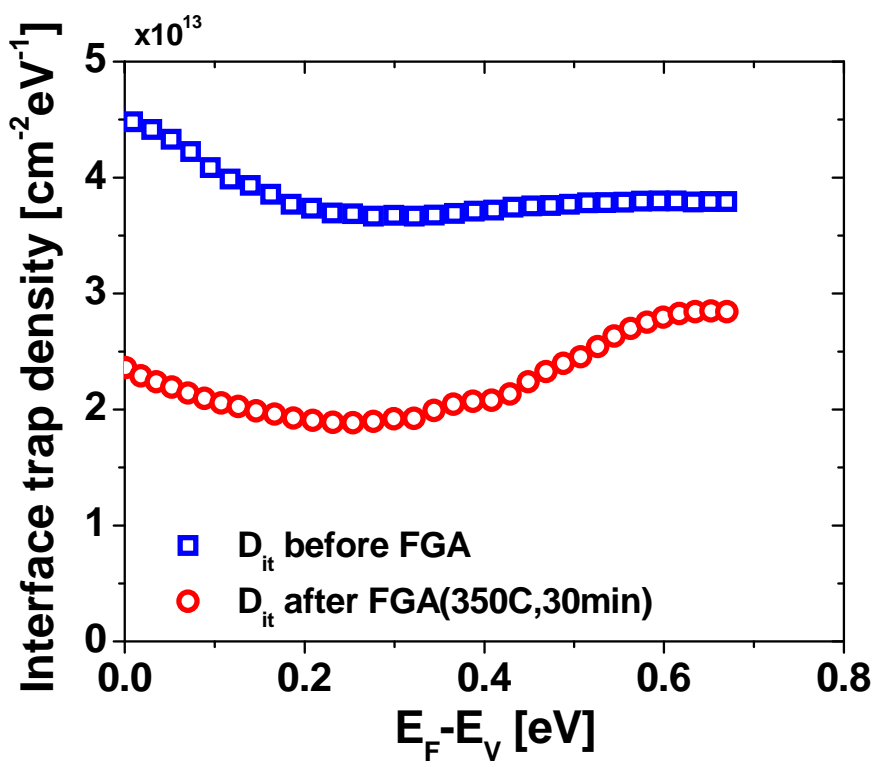

Figure 3. Extracted interface trap density from n-type GaSb MOS capacitors from Process 2 before and after $\mathrm{FGA}$ at $350^{\circ} \mathrm{C}$ for 30 minutes 
Figure 3 shows the interface trap distribution extracted using the conductance method (10) from n-type GaSb MOS capacitors for Process 2 before and after FGA. As seen in the figure, the annealing results in the reduction of the interface trap density in both positive and negative bias regime, although the peak value still remains high (peak $\mathrm{D}_{\mathrm{it}}=2.9 \times 10^{13} \mathrm{~cm}^{-2} \cdot \mathrm{eV}^{-1}$ ).

The measurements of the near-surface minority carrier lifetime $\left(\tau_{\mathrm{ns}}\right)$ in GaSb, which was subjected to three different treatments prior to ALD of $5 \mathrm{~nm} \mathrm{Al}_{2} \mathrm{O}_{3}$, were carried out in order to get additional insight into the effect of surface treatments under investigation on the properties of $\mathrm{Al}_{2} \mathrm{O}_{3}-\mathrm{GaSb}$ interface. It should be pointed out that the PCD method used here allows measurement of the minority carrier lifetime in the near-surface region of semiconductor $(\mathrm{GaSb})$ covered with a layer of dielectric $\left(\mathrm{Al}_{2} \mathrm{O}_{3}\right)$ as long as dielectric is transparent to UV light used for illumination. If this condition is met, as it is in the case of material system of interest in this study, the results obtained are taken as an adequate representation of the condition of the interface region in semiconductor.

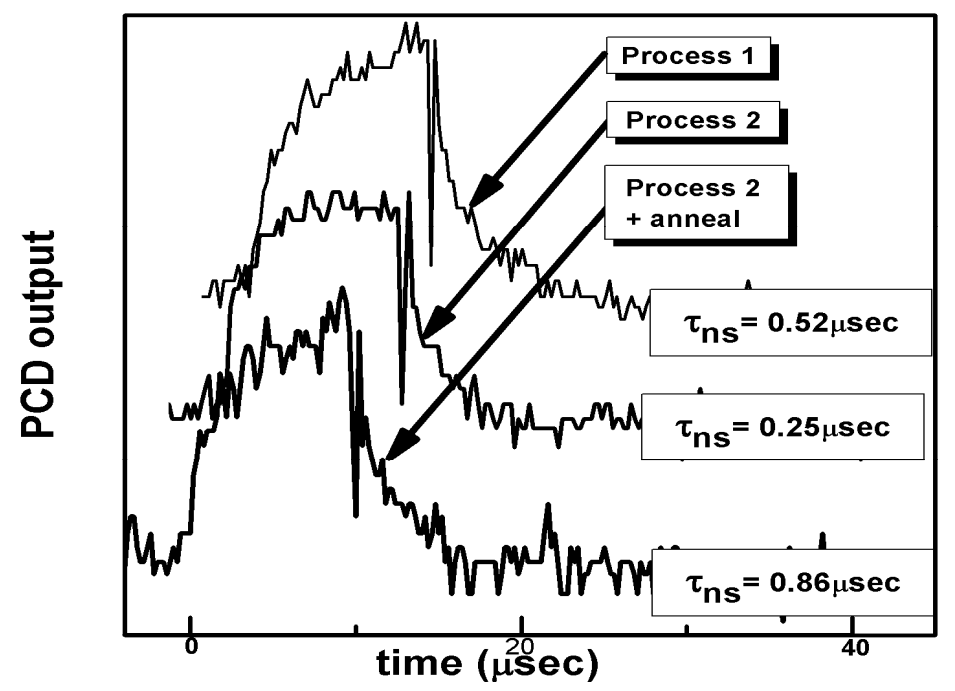

Figure 4 Minority carrier lifetime in $\mathrm{GaSb}$ subjected to three different surface treatments prior to atomic layer deposition of $5 \mathrm{~nm}$ thick $\mathrm{Al}_{2} \mathrm{O}_{3}$ : Processes 1 and 2 are defined in Experimental section.

The $\tau_{\mathrm{ns}}$ was determined from the slope of the plots in Fig. 4 during the initial period of the photoconductive decay before the carriers generated near the surface diffuse into the bulk As the results in Fig. 4 show, very short minority carrier lifetimes were measured indicating overall low quality of the GaSb region near the interface with $\mathrm{Al}_{2} \mathrm{O}_{3}$. For comparison, minority carrier lifetimes measured for single-crystal silicon covered with the same $5 \mathrm{~nm}$ thick $\mathrm{Al}_{2} \mathrm{O}_{3}$ were in the range of 20-30 $\mu$ sec. In spite of the short lifetimes measured the results in Fig. 4 show the difference in photo-conductance decay behavior depending on the processing scheme. The shortest $\tau_{\mathrm{ns}}$ measured for Process 2 is consistent with increased surface roughness observed following native oxide removal in the course of $\mathrm{HCl}$ treatment. The FGA applied after $\mathrm{HCl}$ treatment appears to at least partially remove damage introduced by $\mathrm{HCl}$, although, possibility that the FGA affected other properties of the near-surface region can not be excluded (11). Either way this result is consistent with the effect of FGA on the interface trap density (Fig. 3). By allowing the native oxide on the GaSb surface prior to $\mathrm{Al}_{2} \mathrm{O}_{3}$ deposition, Process 1 results 
in longer lifetime as compared to Process 2, but, as concluded from Fig. 2, is not a viable solution from the point of view capacitance-voltage characteristics.

\section{Conclusions}

The results obtained in this study confirm that the HCl-based treatment of GaSb surface is effective in the removal of native oxides. Even partial removal of the native oxides considerably improves the $\mathrm{C}-\mathrm{V}$ characteristics of metal- $\mathrm{Al}_{2} \mathrm{O}_{3}-\mathrm{GaSb}$ capacitors. At the same time, however, the same process causes shortening of the minority carrier lifetime near the $\mathrm{Al}_{2} \mathrm{O}_{3}$ - $\mathrm{GaSb}$ interface. Further modifications of the GaSb surfaces prior to high-k dielectric deposition can be achieved by forming gas anneal.

Overall, the results obtained in this experiment demonstrate complex interactions between pre-ALD GaSb surface treatments and electrical characteristics of resulting $\mathrm{Al}_{2} \mathrm{O}_{3}-\mathrm{GaSb}$ structures. It is, therefore, important that the process of $\mathrm{GaSb}$ surface preparation for high-k dielectric deposition is carefully optimized. The results obtained also seem to point out to the need to integrate pre-deposition surface treatments of $\mathrm{GaSb}$ with subsequent atomic layer deposition of high-k dielectric.

\section{References}

1. S. Datta, T. Ashley, J. Brask, L. Buckle, M. Doczy, M. Emeny, D. Hayes, K. Hilton, R. Jefferies, T. Martin, T. Phillips, D. Wallis, P. Wilding, and R. Chau, IEEE IEDM Tech. Dig., p763 (2005)

2. T. Ashley, M. T. Emeny, D. G. Hayes, K. P. Hilton, R. Jefferies, J. O. Maclean, S. J. Smith, A. W-H. Tang, D. J. Wallis and P. J. Webber, IEEE IEDM Tech. Dig., p 35.1.1 (2009)

3. M. Radosavljevic, T. Ashley, A. Andreev, S. D. Coomber, G. Dewey, M. T. Emeny, M. Fearn, D. G. Hayes, K. P. Hilton, M. K. Hudait, R. Jefferies, T. Martin, R. Pillarisetty, W. Rachmady, T. Rakshit, S. J. Smith, M. J. Uren, D. J. Wallis, P. J. Wilding, and R. Chau, IEEE IEDM Tech. Dig., p727 (2008)

4. A. Ali, H. Madan, R. Misra, E. Hwang, A. Agrawal, P. Schiffer, J. B. Boos, B. R. Bennett, I. Geppert, M. Eizenberg, S. Datta, IEEE IEDM Tech. Dig., p 6.3.1 (2010).

5. A. Nainani, T. Irisawa, Z. Yuan, Y. Sun, T. Krishnamohan, M. Reason, B. R. Bennett, J. B. Boos, M. G. Ancona, Y. Nishi, K. C. Saraswat, IEEE IEDM Tech. Dig., p 6.4.1 (2010).

6. P. S. Dutta, H. L. Bhat, and V. Kumar, J. Appl. Phys., 81 (9), p5821 (1997)

7. C. L. Lin, Y. K. Su, T. S. Se and W. L. Li, Jpn. J. Appl. Phys., 37-2(12B), p1543 (1998).

8. Z. Y. Liu, B. Hawkins and T. F. Kuech, J. Vac. Sci. Technol. B, 21(1), p71 (2003).

9. P. Drummond, A. Kshirsagar, S. Ramani, and J. Ruzyllo, Thin-Solid Films, in print.

10. E. H. Nicollian and J. R. Brews, MOS (Metal Oxide Semiconductor) Physics and Technology, p. 226, Wiley, New York (1981).

11. P. Roman, J. Staffa, S. Fakhouri. M. Brubaker, K. Torek, E. Kamieniecki, and J. Ruzyllo, J. Appl. Phys., 83, p.538 (1998). 